\title{
The castellated beams deflections calculated with theory of composed bars
}

\author{
A. Pritykin \\ Kaliningrad State Technical University (KGTU), Sovetsky av.1, 236022, Kaliningrad, Russia, E-mail: prit_alex@mail.ru \\ Immanuel Kant Baltic Federal University, A. Nevskogo str. 14, 236041, Kaliningrad, Russia
}

cross rof http://dx.doi.org/10.5755/j01.mech.21.5.12181

\section{Introduction}

In Russian structural Norms SN\&R [1], as in Eurocode 3 [2], one of the basic demand to castellated beams is securing of necessary rigidity, i.e. restriction of relative deflection $f / l$. For different structures admissible value of this magnitude is different, but more often for beams it had to satisfy to condition $f / l \leq 1 / 250$. In SN\&R [1] the relative height of openings in castellated beams is restricted by value $\xi=h / H=0.667$, as more useful in structural practice. Namely beams with such openings will be considered in the article.

For today there are three different methods of calculation of the castellated beams deflections: method based on the theory of composed bars (TCB) [3]; method using the theory of Vierendeel truss [4] and the finite element method (FEM) [5]. First two methods are approximate ones but FEM is an exact method. It's seems the best of all to use FEM for calculation of deflections, but application of FEM demands of existence of rather expensive program complex for modeling of calculated structure (for example, ANSYS) and beside of this a researcher is to be qualified in using ANSYS, so as even small deviations in adopted boundary conditions or description of model can bring to significant distortions in results. That is why different analytical approximate methods are elaborated for prediction of the castellated beams deflections.

In Russian practice the method of the theory of composed bars, elaborated by A.R. Rzanizyn [3] is more popular and in abroad Vierendeel method is widespread, application of which to calculation of castellated beams was even included in one of the previous variants of Eurocode 3 [4]. In the work the task of obtaining reliable relation for prediction of deflections of the castellated beams was put. A criterion of the calculation accuracy is the finite element method results.

Calculation of deformations of perforated beams deflections with the theory of composed bars was modified by author with integration of differential equation in Fourier series [6].

\section{Testing procedures}

Performing of openings in webs of castellated beams lead to reducing of their shear rigidity and hence to increasing of its deflections. For simply supported beams its growth can reach $60 \%$, and for a clamped beams even 2-2.5 times compare to deflections of the same dimensions beams with solid web.

In work it was put problem of comparison of different approaches for calculations of deflections of simply supported castellated beam, loaded with distributed load (Fig. 1) under different relative length $l / H$.

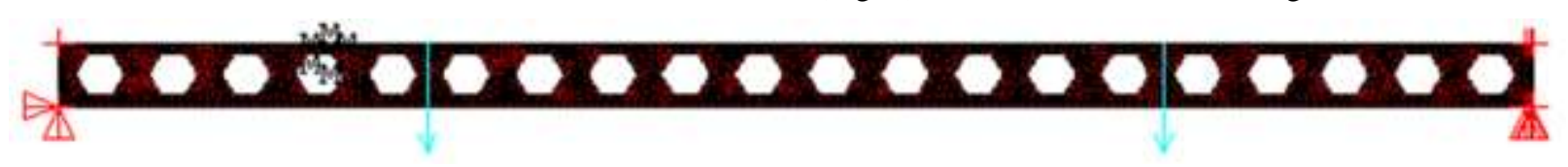

Fig. 1 Scheme of loading of simply supported beam with uniformly distributed load

In the theory of composed bars perforated beam is considering as two bearing T-bars, located above and be- low of openings, and elastic lay, formed with web-posts between openings, involving bars in joint work (Fig. 2).
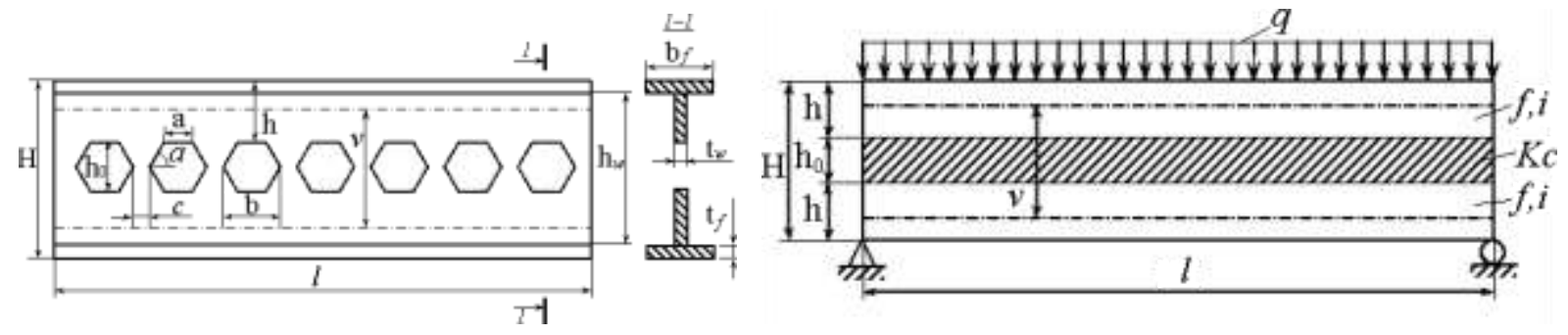

Fig. 2 Geometry parameters and calculation scheme of castellated beam according to TCB

Below it is considering variant of calculation of deflections with TCB based on integration of differential equation in Fourier series. In work [5] differential equation of the flexure axis of composed beam was obtained in form:

$$
w^{\prime \prime \prime}-\frac{I K_{c}}{E f i} w^{\prime \prime}=\frac{M^{\prime \prime}}{E 2 i}-\frac{M K_{c}}{E^{2} f i},
$$


here $E$ is Young modulus of material; $f$ is cross area of every T-belt; $K_{c}$ is coefficient of rigidity of elastic layer, formed with web-posts; $I$ is moment of inertia of beam calculated for weakened by opening section; $i$ is proper moment of inertia of T-belt located above opening; $M$ is flexure moment.

From Eq. (1) as private cases it can be obtained equation of flexure of packet formed with two bars $E 2 i w^{I V}=M^{\prime \prime}$, not jointed between themselves by shear ties $\left(K_{c}=0\right)$, or equation of flexure of monolith beam $E I w^{\prime \prime}=M$ under $K_{c} \rightarrow \infty$.

For obtaining a simple form of solution Eq. (1) was solved in Fourier series for case of action of uniformly distributed load $q$. Then by decomposition of function of flexure moment $M$ in series by sinus:

$$
M=\frac{q l^{2}}{8} \sum_{n=1,3} \frac{1}{n^{3}} \sin n \pi \xi,
$$

solution of Eq. (1) can be obtained in form of series:

$$
w=\frac{4 q l^{4}}{\pi^{5} E I} \sum_{n=1,3} \frac{I / 2 i+K_{c}^{*} / n^{2}}{n^{5}\left(1+K_{c}^{*} / n^{2}\right)} \sin n \pi \xi
$$

here $l$ is length of beam, $\xi=x / l$, and $K_{c}^{*}$ is dimensionless coefficient, determined on relation:

$$
K_{c}^{*}=K_{c} l^{2} I / E f i \pi^{2} .
$$

Analysis of results of calculations by FEM and TCB of castellated beams show that for simply supported beam (Fig. 1), loaded with uniformly distributed load of intensity $q$, good results can be obtained remaining only one term of series in decomposition Eq. (3), changing coefficient $4 / \pi^{5}$ at $5 / 384$. Then instead of Eq. (3) we get:

$$
w_{\text {perf }}=\frac{5 q l^{4}}{384 E I} \frac{I / 2 i+K_{c}^{*}}{1+K_{c}^{*}} .
$$

First multiple in Eq. (5) represents the deflection $w^{T T}$ of simply supported beam, calculated on technical theory of flexure:

$$
w^{T T}=\frac{5 q l^{4}}{384 E I} .
$$

Moment of inertia $I$ calculated for section with opening have a view:

$$
I=I_{\text {sol }}-h_{0}^{3} t_{w} / 12 \text {. }
$$

The inertia moment $I_{\text {sol }}$ of beam with solid web can be calculated approximately as:

$$
I_{\text {sol }} \approx b_{f} t_{f}\left(H-t_{f}\right)^{2} / 2+t_{w}\left(H-2 t_{f}\right)^{3} / 12 .
$$

Expression (8) is approximate so as it is not taken into account proper moment inertia of shelves, influence of which for I-beams usually not exceed $1 \%$.

If take into account that in many cases $K_{c}>100$ it is possible to neglect with unity in denominator of Eq. (5) and write it in more compact form, convenient for practical calculations:

$$
w_{\text {perf }}=w^{T T}\left(1+I / 2 i K_{c}^{*}\right) .
$$

Second additive in brackets in Eq. (9) is reflecting the shear component of web deflection of perforated beam. Although the expression for deflection Eq. (9) has a compact form it can be simplified more if substitute in it Eq. (4). Then relation Eq. (9) can be written as:

$$
w_{\text {perf }}=w^{T T}\left(1+0.5 \pi^{2} E f / K_{c} l^{2}\right) .
$$

For getting of reliable result on theory of composed bars it is need correctly determine coefficient $K_{c}$, which is function of height of opening $h$, relative width of web-post $c / a$, thickness $t_{w}$, material of beam $E$ and form of web-post. Incorrect finding of value $K_{c}$ can lead to essential loss of accuracy in calculations of the beam deflections.

Unknown coefficient $K_{c}$ can be determined from experiment on static testing of perforated beam or using results of numerical calculation of beam by FEM. In the work it was used second approach. Coefficient of rigidity $K_{c}$ can be calculated as:

$$
K_{c}=\frac{G t_{w}}{\alpha(\eta) h_{0}(1+2 / \eta)},
$$

where $G=E /(2(1+\mu))$ is shear modulus; $\mu=0.3$ is Poisson factor; $t_{w}$ is thickness of web; $h_{0}$ is height of openings; $\eta=c / a$ is relative width of web-post; $c$ is minimum width of web-posts; $a$ is side of hexagonal opening; $\alpha(\eta)$ is numerical coefficient depending on way of fixing beam (simply supported or clamped) and on relative width of web-post $\eta$.

Today in structural practice cellular beams with narrow web-posts (Fig. 3, a) are applied widely. Technology of the castellated beams performing suggested by author [7] allow to get any width of web-post independently of side of opening (Fig. 3,b). That is why coefficient $\alpha(\eta)$ was chosen as function of $\eta$.

For s imply supported beam with height of openings $h_{0}=0.667 H$ coefficient $\alpha(\eta)$ have a view:

$$
\alpha(\eta)=-2.43 \eta^{2}+4.54 \eta+0.586
$$

Using of relation Eq. (12) lead to good results for any width of web-post in range $0.3 \leq \eta \leq 1$. Substitution of Eq. (11) into Eq. (10) lead to:

$$
w_{\text {perf }}=w^{T T}\left(1+1.3 \pi^{2} h_{0} f \alpha(\eta)(1+2 / \eta) / t_{w} l^{2}\right) .
$$




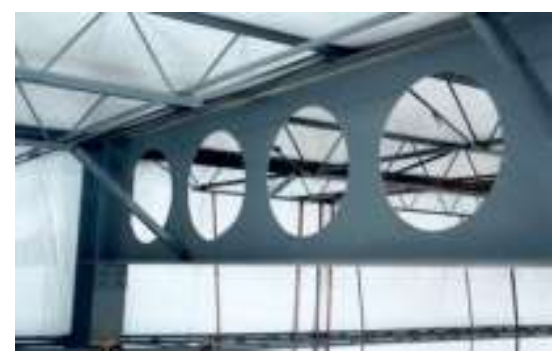

a

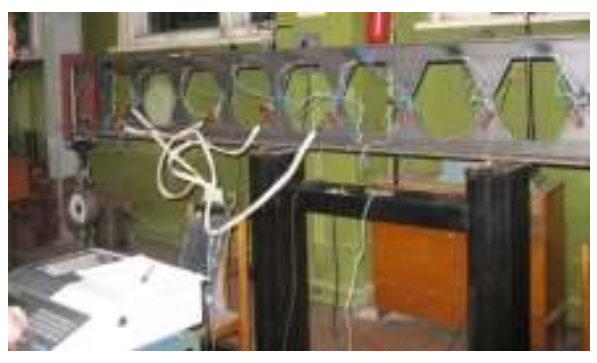

b

Fig. 3 Perforated beams with narrow web-posts: a - circular; b - hexagonal openings

So, deflection of perforated beam according to theory of composed bars can be easy calculated on relation Eq. (13), if it is known load, parameters of perforation and dimensions of beam. All calculations of deflections on TCB are convenient to perform with help of electronic tables Excel. Area $f$ of T-belt can be calculated as:

$$
f=t_{f} b_{f}+t_{w}\left(0.5\left(H-h_{0}\right)-t_{f}\right) .
$$

Preliminary calculations by FEM showed that better results can be obtained if instead of $I$ in relation Eq. (6) use the inertia moment $I_{m}$ determined as average arithmetic of the inertia moments calculated in two cross sections: in cross section without opening $I_{\text {sol }}$ Eq. (8) and in cross section with opening $I$ Eq. (7):

$$
\begin{aligned}
I_{m} \approx & b_{f} t_{f}\left(H-t_{f}\right)^{2} / 2+ \\
& +t_{w}\left(H-2 t_{f}\right)^{3} / 12-t_{w} h_{0}^{3} / 24 .
\end{aligned}
$$

Namely relation Eq. (13) will be used below for calculation of deformations of simply supported beams and only in expression for $w^{T T}$ Eq. (6) it is need to substitute the inertia moment $I_{m}$.

\section{Numerical calculation of deflections of castellated beams}

Estimation of accuracy of obtained above analytical relation is possible by comparison of numerical results with calculations performed by FEM, which are most reliable. For that it was considered simply supported castellated beams with different values of the web-post slenderness $\lambda_{w} \approx H / t_{w}$. It was calculated three beams with $\lambda_{w} \approx 60 / 0.86=70 ; \quad \lambda_{w} \approx 75 / 0.6=125 \quad$ and $\lambda_{w} \approx 120 / 0.6=200$, because with increasing of the web slenderness the influence of perforation at deflections under same relative height of openings is grow. It can be concluded from the second term in Eq. (13), which is proportional to value $h / t_{w}$.

As it is known the perforated beams with hexagonal openings are being extensively used in lightly loaded and long-span composite floor constructions, for example, in multy-level parking garages. Castellated beams are being pushed to span great lengths which can approach 16-28 m under height of beam $H \leq 820 \mathrm{~mm}$, i. e. relative length of such beams can varied in big diapason. That is why in calculation below variants of beams with relative length
$10 \leq l / H \leq 40$ were considered.

First beam had dimensions: $l-60-0.86-18-$ $-1.35 \mathrm{~cm}-0.667-1$ which can be interpreted as $l-H-t_{w}-b_{f}-t_{f} \mathrm{~cm}-h / H-c / a$ i. e. length - height web thickness of beam - width of shelves - thickness of shelves - relative height of opening - relative width of web-post. Load on beam was uniformly distributed with intensity $q=10 \mathrm{kN} / \mathrm{m}$. Calculations were performed for beams with relative length changing in diapason $10 \leq h / H \leq 40$. Parameters of first calculated beam were next: $q=10 \mathrm{kN} / \mathrm{m} ; l=900 \mathrm{~cm} ; E=2.1 \cdot 10^{5} \mathrm{MPa}$ :

$$
G=\frac{E}{2(1+\mu)}=\frac{2.1 \cdot 10^{5}}{2(1+0.3)}=8.08 \cdot 10^{4} \mathrm{MPa} .
$$

The inertia moment of beam $I_{m}$ according to Eq. (15) is:

$$
\begin{aligned}
I_{m}= & 18 \cdot 1.35(60-0.86)^{2} / 2+0.86(60-2 \cdot 0.86)^{3} / \\
& / 12-0.86 \cdot 40^{3} / 24=52980 \mathrm{~cm}^{4}
\end{aligned}
$$

Deflection of beam $w^{T T}$ (6) will be:

$w^{T T}=\frac{5 q l^{4}}{384 E I_{m}}=\frac{5 \cdot 10 \cdot 9000^{4}}{384 \cdot 2.1 \cdot 10^{5} \cdot 52980 \cdot 10^{4}}=7.68 \mathrm{~mm}$

Area of T-belt is determining as Eq. (14):

$$
\begin{aligned}
f= & b_{f} t_{f}+\left(0.5\left(H-h_{0}\right)-t_{f}\right) t_{w}=18 \cdot 1.35+ \\
& +(0.5(60-40)-1.35) 0.86=31.7 \mathrm{~cm}^{2}
\end{aligned}
$$

Then calculation of deflection Eq. (13) gives:

$$
\begin{gathered}
w_{\text {perf }}= \\
\quad 7.68\left(1+1.3 \pi^{2} \cdot 40 \cdot 31.7 \cdot 2.7(1+2) /\right. \\
\left./\left(0.86 \cdot 900^{2}\right)\right)=9.12 \mathrm{~mm} .
\end{gathered}
$$

The finite element calculations bring to value $w_{\text {perf }}^{F E M}=9.24 \mathrm{~mm}$. As it can be seen divergence with the FEM is $1.3 \%$.

Results of calculations of 3 types of beams for different relative length of beam with dimensions: $l-60-0.86-18-1.35 \mathrm{~cm}-0.667-1$; $l-75-0.6-17-1.52 \mathrm{~cm}-0.667-1$ and $l-120-0.6-30-2 \mathrm{~cm}-0.667-1$ are shown in Ta- 
ble 1. As it can be seen from Table 1, accuracy of calculation on TCB is rather high; divergence with FEM does not exceed $2.5 \%$ even for shot beams. As it is known, biggest effect of shear on deflections is registered for shot and high beams, i.e. beams with small ratio $l / H$.

Calculation of deflections with FEM was performed with program complex ANSYS using quadrangular elements Shell63 with 6 degrees of freedom in every node. Characteristics of material were: modulus of elasticity $E=2.1 \cdot 10^{5} \mathrm{MPa}$ and Poisson coefficient $\mu=0.3$. Mesh of elements was uniform with size $\Delta_{F E}=2 \mathrm{~cm}$. Such ap- proach joins simple modeling with good results. Using of elements Shell63 the thickness of which is attribute it is need height of web adopt equal $H-t_{f}$, then real height of model will be equal full height of beam $H$. Due to symmetry it is possible consider only half a beam that sufficiently reduce time of calculations.

Performed with FEM calculations of beams $l-60-0.86-18-1.35 \mathrm{~cm}-0.667-1$ with different length are shown in Fig. 4.

Deflections (mm) of the simply supported castellated beams, uniformly loaded $q=10 \mathrm{kN} / \mathrm{m}$

Table 1

\begin{tabular}{|c|c|c|c|c|c|c|c|c|}
\hline \multirow{2}{*}{ Method of calculation } & \multicolumn{8}{|c|}{ Relative length of beam, $l / H$} \\
\hline & 10 & 12 & 15 & 20 & 25 & 30 & 35 & 40 \\
\hline & \multicolumn{8}{|c|}{$l-60-0.86-18-1.35 \mathrm{~cm}-0.667-1$} \\
\hline TCB & 2.16 & 4.07 & 9.12 & 26.8 & 63.3 & 128.6 & 235.5 & 398.5 \\
\hline FEM & 2.16 & 4.12 & 9.24 & 26.8 & 63.1 & 128.3 & 234.7 & 396.1 \\
\hline \multirow[t]{2}{*}{ Divergence, $\%$} & 0 & -1.2 & -1.3 & 0 & 0.3 & 0.2 & 0.3 & 0.6 \\
\hline & \multicolumn{8}{|c|}{$l-75-0.6-17-1.52 \mathrm{~cm}-0.667-1$} \\
\hline TCB & 3.44 & 6.41 & 14.2 & 41.4 & 97.0 & 196.6 & 359.3 & 607.3 \\
\hline FEM & 3.41 & 6.407 & 14.2 & 41.3 & 96.3 & 196.5 & 357.3 & 605.3 \\
\hline \multirow[t]{2}{*}{ Divergence, $\%$} & 0.9 & 0 & 0 & 0.3 & 0.7 & 0 & 0.5 & 0.3 \\
\hline & \multicolumn{8}{|c|}{$l-120-0.6-30-2.0 \mathrm{~cm}-0.667-1$} \\
\hline TCB & 4.46 & 8.11 & 17.5 & 49.8 & 115.3 & 231.9 & 421.6 & 710.4 \\
\hline FEM & 4.36 & 8.09 & 17.7 & 49.4 & 114.3 & 229.1 & 419.1 & 704.5 \\
\hline Divergence, $\%$ & 2.3 & 0.2 & 1.1 & 0.8 & 0.9 & 1.2 & 0.6 & 0.8 \\
\hline
\end{tabular}

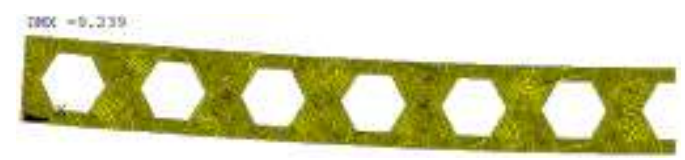

a

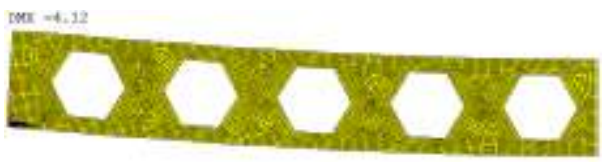

b

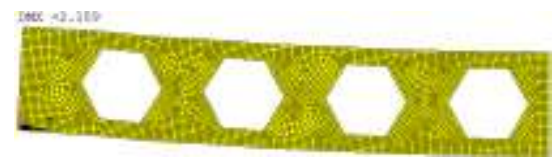

C

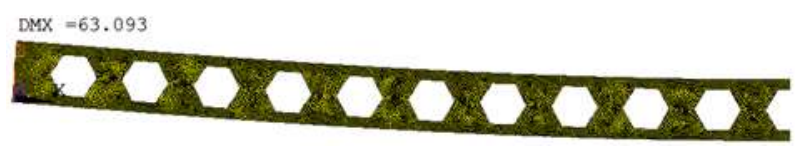

d

Fig. 4 Deflections of simply supported beams $l-60-0.86-18-1.35 \mathrm{~cm}-0.667-1$ under distributed load $q=10 \mathrm{kN} / \mathrm{m}$ : $\mathrm{a}-l=6 \mathrm{~m} ; \mathrm{b}-l=7.2 \mathrm{~m} ; \mathrm{c}-l=9 \mathrm{~m} ; \mathrm{d}-l=15 \mathrm{~m} ; \mathrm{e}-l=18 \mathrm{~m}$

In Table 2 results of calculation by FEM and TCB of castellated beams with narrow web-posts are shown. Width of web-post in first case was equal to $c=0.3 a$ of horizontal side of opening and in second case $c=0.5 a$. As it can be seen accuracy of calculation on TCB is even better than for beams with wide web-posts. Influence of width of web-posts on deflections is not big; for beams with length $l \geq 25 H$ it does not exceed $5 \%$.

Results of calculation of deflections of castellated beams with narrow web-posts by FEM are shown in Fig. 5. As it can be seen divergence between deflections of beams with relative web-posts $\eta=0.3$ and web-posts $\eta=0.5$ is less of $4 \%$ for beams with relative length $l / H \geq 15$ (see Table 2).

If compare deflections of perforated beam and beam with solid web $(l=900 \mathrm{~cm})$ it can be seen (Fig. 5, c) the openings reduce rigidity of beam approximately at $23 \%$ for classic perforation with $\eta=1$ and at $31 \%$ for perforation with $\eta=0.3$. For short beams ( $l / H=10$ ) the influence of perforation is increasing up to $60 \%$. 
Table 2

Deflections (mm) of the simply supported castellated beams with narrow web-posts, load $q=10 \mathrm{kN} / \mathrm{m}$

\begin{tabular}{|c|c|c|c|c|c|c|c|c|}
\hline \multirow{2}{*}{ Method of calculation } & \multicolumn{8}{|c|}{ Relative length of beam, $l / H$} \\
\hline & 10 & 12 & 15 & 20 & 25 & 30 & 35 & 40 \\
\hline & \multicolumn{8}{|c|}{$l-60-0.86-18-1.35 \mathrm{~cm}-0.667-0.3$} \\
\hline TCB & 2.56 & 4.65 & 10.0 & 28.5 & 65.8 & 132.3 & 240.5 & 405.1 \\
\hline FEM & 2.61 & 4.64 & 9.87 & 28.5 & 65.7 & 132.2 & 240.5 & 405.2 \\
\hline \multirow[t]{2}{*}{ Divergence, $\%$} & -1.9 & 0.2 & 1.3 & 0 & 0.2 & 0.1 & 0 & 0 \\
\hline & \multicolumn{8}{|c|}{$l-60-0.86-18-1.35 \mathrm{~cm}-0.667-0.5$} \\
\hline TCB & 2.40 & 4.42 & 9.68 & 27.8 & 64.8 & 130.9 & 238.5 & 402.5 \\
\hline FEM & 2.40 & 4.40 & 9.53 & 27.6 & 65.3 & 130.7 & 238.5 & 401.3 \\
\hline Divergence, $\%$ & 0 & 0.5 & 1.6 & 0.7 & 0.8 & 0.2 & 0 & 0.3 \\
\hline
\end{tabular}

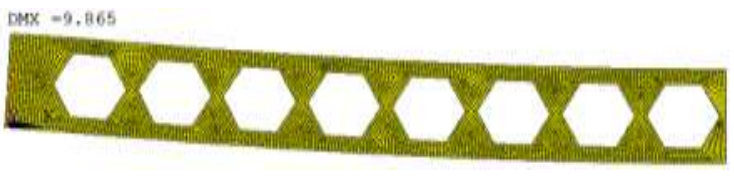

a

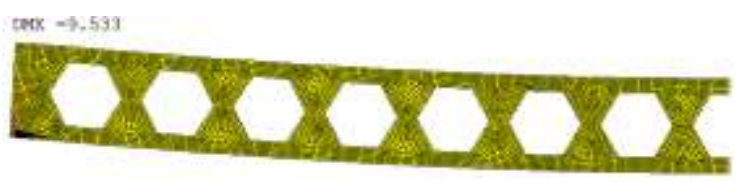

$\mathrm{b}$

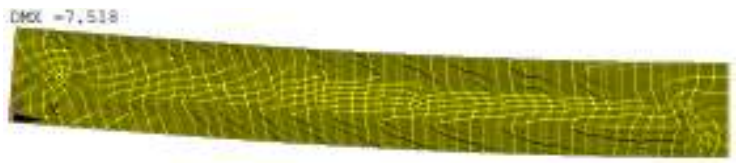

C

Fig. 5 Deflections of simply supported beams 900-60$-0.86-18-1.35 \mathrm{~cm}-0.667-\eta$ with narrow webposts: a $-\eta=0.3 ; b-\eta=0.5$; - with solid web

\section{Conclusions}

1. Theory of composed bars is quite applicable to prediction of deflections of perforated beams.

2 . Obtained results show the deflections of castellated beams with height of openings $h=0.667 H$ can be determined with good accuracy on relation Eq. (13) for any width of web-posts in limits $0.3 \leq \eta \leq 1$. Divergence with FEM does not exceed $3 \%$.

3. For relative length $l / H>30$ it is not need to use relation (13) because good results give calculation of deflection with the technical theory of flexure Eq. (6) using an average inertia moment $I_{m}$. Divergence with FEM results is less $1 \%$.

4. The obtained relation Eq. (13) can be recommended for including in Structural Norms \& Rules for prediction of the castellated beams deflections.

\section{References}

1. SN\&R II-23-81* Steel Structures. Norms of Design.
1991. 96p. (in Russian).

2. Eurocode 3. EN 1993-1-5:2005. - Design of steel structures - Part 1.5. - Brussel: European Committee on Standartization. 53 p.

3. Rzanizyn, A. 1986. Composite Bars and Plates. - M., Strojizdat. 316p (in Russian).

4. Eurocode 3. ENV 1993-1-1:1993. Design of steel structures. - Annex N: Openings in webs. European Committee for Standardization.

5. Hrabok, M.; Hosain, M. 1977. Castellated beams deflections using substructuring, J. of the Structural Division Proceedings of the ASCE 103(1): 265-269.

6. Pritykin, A. 2012. Influence of shear on deformations of perforated beams with hexagonal openings, Izvestia vuzov, Construction 3: 111-118 (in Russian).

\section{A. Pritykin}

\section{THE CASTELLATED BEAMS DEFLECTIONS CALCULATED WITH THEORY OF COMPOSED BARS}

S u m m a r y

In the article it was investigated deflections of the castellated beams using the theory of composite bars. Differential equation of the flexure axis of composed beam was integrated with Fourier series. Reliable expression for deflection was obtained due to good choice of the rigidity coefficient of elastic lay formed with web-posts. Analytical solution for deflection is applicable for wide range of perforations: $l / H \geq 10 ; 0.3 \leq c / a \leq 1 ; h_{0}=0.667 H$. An accuracy of obtained relation was estimated with calculations by the finite element method. Divergence of results does not exceed $3 \%$.

Keywords: deflection, castellated beams, hexagonal openings, theory of composite bars, coefficient of rigidity of elastically, FEM. 